\title{
A Discussion About Several Teaching Methods Commonly Used in Art Courses
}

\author{
Xiaobo Ren \\ Wenshan College \\ Wenshan, China 663000
}

\author{
Qingna Li \\ Wenshan College \\ Wenshan, China 663000
}

\begin{abstract}
Art course teaching aims at teaching students basic knowledge of art and painting skills, and then disseminates aesthetic culture. At the same time, with the art works as a medium, the teacher can cultivate various abilities of students' aesthetics, moral sentiment, imagination and creativity by reasonably applying a variety of teaching methods and comprehensive practices. Art education can make students have the ideal, the sentiment, the character and the quality of beauty, and have the ability to enjoy and create beauty at the same time. It plays an irreplaceable role in improving students' overall quality and promoting their allround development. This article combines a variety of teaching practice cases and elaborate several commonly used teaching methods and applications in order to provide a model for the future development of art education.
\end{abstract}

Keywords-art education; teaching method; art courses

\section{INTRODUCTION}

The subjects of art courses include teaching purposes, teaching tasks, teaching content, teaching and learning methods, teaching practice and students' teaching feedback. Art teachers take art knowledge and exquisite practical skills of professional systems as the foundation to study art teaching theory and explore its teaching rules to guide teaching practice and improve teaching quality. In the process of promoting quality education in modern society, more and more people realize that art education has a unique role in improving quality education. Teaching methods are the behaviors, procedures and techniques in general that teacher use to organize and guide students in order to achieve a certain teaching goal. ${ }^{1}$ From the art teaching methods, each teacher has its own unique teaching characteristics, combines with their characteristics and presents a variety of teaching methods.

\section{Teaching Methods Based on Language to TRANSMIT INFORMATION}

\section{A. Lecture Method}

Lecture method is the most commonly used teaching method that teachers impart art knowledge by language

Research on Evaluation Criteria and Methods of High School Art Appreciation Teaching, master's degree thesis of Sichuan Normal University,He Pingwei,June 2017 description, explanation and analysis to make students have motivation to learn knowledge. This method has very strict requirements on the language expression and knowledge accumulation of teachers, because simply teaching cannot arouse students' full attention. Lecture method can make students more fully understand the teaching task of knowledge points, and teachers' form of teaching language should confirm the language adaptability of the teaching object, clear, accuracy and refined. It should not only easy to understand and vivid, but also full of contagious and using humorous language, combining with graphic can play a good teaching effect.

\section{B. Conversation Method (Question and Answer Method)}

Conversation method is a way for teachers and students to communicate in spoken language and communicate with each other on an equal basis. It involves a smaller range of students, focus on student attention and develops students' thinking in the classroom, it is suitable for small classes or targeted teaching. However, due to the different thinking skills of students in the conversation method, the questions raised will be "all sorts of strange things", which requires teachers to be fully prepared before class, and the difficulty of teaching language and problem setting should be fairly well-researched. Otherwise, it will leads to the chaos of teaching lesson easily. Through the method of conversation, we can learn more about students' understanding of teaching contents by equal communication with students. In combination with the actual situation of students, students should be taught and guided according to their aptitudes. Students should be encouraged to speak boldly in the encouraged language while proposing imaginative and creative issues.

\section{Discussion Method}

Under the guidance of teachers, the students in groups or teams as a unit, teachers organize students to discuss about a certain teaching problem, express one's own opinions, inspire each other or debate, so as to obtain or consolidate the teaching method of art knowledge, namely the discussion method. In the actual teaching, classroom discussion is an essential part to let students learn to think and solve the problem, and then the teacher evaluate it and give a suitable advice, so that students learn to understand the perspective and starting point for thinking and use in practical learning, to achieve the purpose of learning. 


\section{Reading and Directing Method}

Teachers guide students to gain knowledge through independent reading art textbooks and extracurricular art information, can be called reading and directing method. This method can broaden students' horizons of art, enhance students' active learning awareness and correct learning attitude when teaching conceptual nouns in teaching, students can read the books to find them. After teachers' narration and analysis, students' comprehension and memory can be strengthened. It is an important part of the teaching process in the course. This requires teachers to inform students the scope of reading materials in advance, so that students can understand the theme-based curriculum knowledge quickly under the guidance and this also avoids blind reading. For example, when it comes to Qi Baishi, teachers can let students understand his life, his most representative works and make comments, it is not only deepens students' ability to keep in mind of the teaching content, but also increases students' sense of self-confidence due to learning knowledge of masters.

\section{TEACHING METHOds BASED ON DIRECT PERCEPTION}

\section{A. Demo Operation Method}

Demo operation method means that during the art teaching process, teachers can prepare some teaching aids or demonstrative works according to the contents of the course, by allowing students to observe and experience, from which to obtain the teaching of realism and to enhance interest in learning. For example, when using demo operation method in teaching courses, teachers should let students appreciate traditional Chinese painting works, teachers should explain each piece of work so that students can make different opinions, then teachers do an example and allow each student to observe the operation process, so as to mobilize the students' thinking and imagination and enhance students' art knowledge and accomplishment. This is one of the main methods commonly used in art courses. It can be divided into full demonstration, important and difficult demonstration and synchronous demonstration of teachers and students.

\section{B. Visiting Method}

The visiting learning method is that teachers actively organize students to visit and learn in a strong artistic atmosphere, so that students can immerse themselves in the atmosphere and feel strong learning atmosphere, such as museums, calligraphy and painting exhibitions, science and technology exhibitions and other art exhibitions. For example, teachers take students to the training room in the middle school art teaching. There are paintings, handicrafts and still life placed in the training room, which add a strong learning atmosphere and make students feel novel. In this way, students' observation ability and aesthetic ability are cultivated. At the same time, it is also a better teaching form for patriotism, revolutionary tradition and red theme education.

\section{Comparative Analysis Method}

Comparative analysis refers to the art teacher through the work or thing comparative analysis and contrast in the teaching process, so that students can understand the theoretical knowledge and skills. For example, in the teaching of art courses, the teacher compares several paintings or several painters, different artistic styles need different appreciation angle, different styles reflect the characteristics of the times, the background of the times, the content is not the same. It can arouse students' attention and discuss and analyze the reasons, so as to stimulate students' enthusiasm for thinking. The purpose is to enable students to learn to understand and analyze different styles of art works.

\section{TEACHING Methods Based on PRACTICE}

The practical training-based teaching method is a method for students to improve their learning interest and knowledge mastery under the guidance of teachers. It is also a teaching method to form, consolidate and improve the corresponding skills and knowledge. It can promote the coordination of students' use of both the brain in art activities so as to cultivate and develop the ability of art creation and imagination. Professor Yin Shaochun of Capital Normal University divides art teaching resources into human resources, materials and equipment resources as well as local arts curriculum resources. He believes that art teachers and materials and equipment resources are two very important basic resources for art teaching. Applying these teaching resources to practice-oriented teaching is an effective assistant for art teachers.

For example, in the "ink painting" course, for most junior high school students, first contact is a course full of curiosity and freshness. Although it is difficult to draw ink paintings, teachers' classroom demonstrations can infect the emotion of students and enhance their interest in learning so that they can receive good learning results. This requires that the demonstration teachers should be skilled in writing and ink, and the paper should be fixed on the blackboard, so that every student can see it. Through the teachers' demonstration, ink color on paper walk freely, brush moves freely like the game, it can appears plum, lotus, chrysanthemum, orchid leaves and other works, students are suddenly presented works attracted, will not produce any learning psychological pressure, but also feel admiration. Students are naturally interested in the teaching and the effect is generally not bad.

For example, some card designs, greeting cards, friendship cards, family cards and greetings cards that students often see in life may seem simple, but students rarely draw it. If these cards look good and refined, they not only can pull into the feelings between people but also let the others to understand the sincerity of the card-delivery person. In the similar teaching content of courses, teachers can draw graphics on the blackboard (square, round and irregular graphics), ask the students to design the greeting card in the graphic, fully mobilize the students' attention, and then take the students appreciate the fine cards, this kind of thinking before acting and imagination not only allows students highly concentrated during the entire class, but also allows 
students to present their own work in the class, it can even induce students with very strong interest to practice teaching content many times after class.

Through the above two practice cases, this class can quickly attract students, teaching effect is remarkable, and reflect the teachers' changing teaching methods and the ability to control the classroom.

\section{Teaching Methods Based on Assessment ACTIVITIES}

\section{A. Appreciation Method}

Appreciation method refers to a teaching method used by teachers in the teaching process. The purpose is to enable students to understand fine art works, to better understand art works and to develop students' emotional thinking through teachers' explanations of fine art works. Marx said: "The object of art creates people that understands art and appreciates art." For example, teachers should choose representative works that can be exchanged with students and analyzed and discussed in art appreciation teaching. At the same time, teachers should also inspire and guide students to think about issues and encourage students to carry out a variety of art appreciation activities, stimulate students' interest in art so as to enhance students' aesthetic abilities.

\section{B. Situation Method}

Situation method refer to teachers adding some music, short video or other content that appropriate the content of the course in the teaching process, in order to activate the classroom, enhance the teaching effect, the classroom atmosphere is not boring and stimulate students' learning motivation and attract students. Mr. Chang Ruilun once pointed out: "art learning is to obtain understanding in the art experience of expressing feelings, learning subjects are not involved in emotion, unable to enter learning state, unable to observe and express art, and cannot create art, the feeling of aesthetics can also be affected by emotions, so learning emotion and feeling play an important role in the learning effect of art subjects."

In some sense, art education is an emotional education. The same is true of ordinary art teaching process, the entire teaching process should create a full emotional atmosphere. On the one hand, it can arouse students' interest and enthusiasm for art study and form a good state of mind. It also helps students to experience and understand art works and fine arts activities, and more conducive to students' creative ability. ${ }^{2}$ For example, when adding situation methods into the classroom of "freehand flower and bird", teachers should choose a contextual atmosphere that matches the teaching content. When teachers make demonstrations, they should be accompanied by pure classical music to enable students to quickly enter the classroom atmosphere and pay attention to the teachers' fan painting, the same classical

\footnotetext{
High school art appreciation class teaching, Yang Lingbin, Inner Mongolia Normal University master's thesis, June 2017
}

music is attached to the students' practice, and the students experience different kinds of learning pleasure with more enthusiasm and initiative in learning, such teaching methods improve the teaching effect and show the diversification of art teaching. The above two teaching methods are teachers' comments on works during the teaching process, so that students can understand their cultural connotation, help students learn to analyze and evaluate works, and cultivate students' correct aesthetic taste and aesthetic ability.

\section{TEACHING Methods Based ON GuIDANCE AND EXPLORATION}

\section{A. Observational Method}

Observational method refers to teachers in teaching, according to the teaching content to arrange some tasks so that students through observation, analysis and research and fulfill their tasks, gain knowledge and feelings and have more enthusiasm and initiative in learning. For example, teachers in the class of still life painting use this method to break the constraints of the classroom and books so that teaching and life are closely linked, feel the things in life and perceive the beauty from everyday life. For example, in drawing lessons, observation of the proportion of still life takes the length and width of the object as the standard, resulting in a long and wide ratio. Drawing the ratio between objects takes one of the objects as the standard. The inclination angle of object is based on the vertical and horizontal lines as a standard for comparison and observation, including teachers in the evaluation of the fine work of students should also be excellent work as a comparative standard.

Yang Jingzhi, a child art educator, in his book Art Education and Human Development once wrote: "I have heard a very vivid and interesting decoration lesson from $\mathrm{Mr}$. Zhou Songsheng in Shanghai, the teacher put the subject into a cloth bag, do not speak what specific thing inside and let the students touch to feel the image by hand, make a kind of mysterious atmosphere, requires students according to their own sense of touch to draw the image and decorate it. Then ask the students to hang the picture on the blackboard, so a variety of teapot designs hang over the blackboard. As the activity progressed, the classroom always laughed and the atmosphere is very active. Finally, teachers and students make comment on homework."3

\section{B. Discovery Method}

The discovery method refers to setting questions related to the content of course during the teaching process, just like previewing, allow students to find out and read textbooks by themselves and research and solve problems given by teachers, learn from independent thinking of middle school students and solve the problem. For example, in "still life" teaching, teachers place the still life so that the students can discover the difference between the still life, at the same time

\footnotetext{
Cultivating junior high school students interest in learning art with a pleasant teaching method,Ma Chunyan, Inner Mongolia Normal University, May 2012
} 
highlight the difference of the still life in the painting with different expressions, under the guidance of the teacher, arouse the students' creative thinking and learn to solve the problem so that teaching can reach the effect of expanding the students' thinking ability.

Art education is inseparable from observation, and observation is always accompanied by the discovery. Through in-depth observation to obtain perceptual knowledge, without observation, there is no vision and perception, it may not have the correct perception and accurate judgment, through these experiences and find more internal relations of things, and this is also the big fun of teaching methods based on guidance and exploration.

\section{CONCLUSION}

The effectiveness of teaching is reflected in what effective teaching methods teachers adopt and whether students have the interest in learning what teachers teach. Teachers use new and varied teaching methods based on their years of teaching experience, should be not only its long-term teaching practice activities continue to summarize the teaching experience, but also the result of its in-depth understanding of students, familiar with the teaching materials and teaching students in accordance with their aptitude. Correct use of appropriate teaching methods in fine arts teaching helps art subjects to achieve their discipline education and quality education, while helping students to master a certain amount of art skills and enhance their interest in learning, it also helps to develop students' healthy emotional and aesthetic awareness. In the actual process, the fact that art knowledge involves various fields of life, a single teaching method cannot adapt to the current classroom teaching. Therefore, we often use a variety of teaching methods in our courses to achieve good teaching results.

\section{REFERENCES}

[1] He Pingwei. Research on Evaluation Criteria and Methods of High School Art Appreciation Teaching, master's degree thesis of Sichuan Normal University, June 2017.

[2] Yang Lingbin. High School Art Appreciation Class Teaching ,Inner Mongolia Normal University master's thesis, June 2017.

[3] Ma Chunyan. Cultivating Junior High School Students Interest in Learning Art with a Pleasant Teaching Method, Inner Mongolia Normal University, May, 2012.

[4] Cao Weiye, Shu Yanhong. Art Courses and Teaching [I].Guangdong: Guangdong Higher Education Press. 2014 (10).

[5] Rong Jingxian, Qian She. Microteaching and Microresearching[M]. Shanghai: East China Normal University Press. 2005 (03).

[6] Wang Dagen. Art Teaching Theory [M].Shanghai:East China Normal University Press.2007 (10). 